Dr Petar Stanojević, major, dipl. inž. dr Vasilije Mišković, pukovnik, dipl. inž. Vojna akademija - ŠNO,
Beograd

\section{MOGUĆNOSTI I PROBLEMI PRIMENE
SAVREMENIH STRATEGIJA ODRŽAVANJA U \\ MOGUCNOSTI I PROBLEMI PRIMENE VOJNIM SISTEMIMA}

UDC: $62-7.001 .26: 355.1$

Rezime:

U radu su analizirani načini i problemi uvođenja savremenih strategija održavanja na osnovu svetskih iskustava. Na osnovu analize stanja održavanja u vojnim sistemima, našem $i$ inostranim, dat je predlog o tome koje bi se strategije održavanja mogle primeniti, pod kojim uslovima $i$ u kakvoj kombinaciji. Analiziran je $i$ način njihovog uvođenja i primene, $i$ date su odgovarajuće preporuke. Izvršena je kratka analiza mogućih efekata.

Ključne reči: strategije održavanja, vojska, problemi primene.

\title{
POSSIBILITIES AND PROBLEMS IN APPLYING CONTEMPORARY MAINTENANCE STRATEGIES TO MILITARY SYSTEMS
}

Summary:

The paper gives problems and methods of introducing contemporary maintenance strategies on the basis of worldwide experiences. The analysis of maintenance in our as well as in other military systems resulted in suggesting possible strategies, conditions of their application and possible combinations. The method of their implementation and application is analyzed as well as possible effects. Adequate recommendations are also given.

Key words: maintenance strategies, military, application problems.

\section{Četvrta generacija organizacija sistema održavanja}

Četvrta generacija organizacija sistema održavanja svoje osnove će imati u prve tri generacije ovih sistema (o prve tri bilo je više reči u VTG br. 6/2003). Karakteristike ove faze biće [1]:

- detaljno i eksplicitno uzimanje u obzir rizika koje nose projektovanje tehničkih sistema (TS) i primena strategija održavanja;

- još veće povezivanje i integracija među naručiocima opreme, projektanti- ma, proizvođačima i održavaocima nego što je to danas. Predlaže se formiranje posebne organizacione funkcije tzv. „Asset management", koja bi se bavila samo upravljanjem TS (naručivanje, nabavka, projektovanje, proizvodnja, održavanje). To, inače, znači i interdisciplinarni pristup rešavanju problema;

- sve veća upotreba informacione tehnologije $u$ otkrivanju, dijagnostici i predviđanju otkaza (prenosni kompjuteri, daljinske komande, GPS za pozicioniranje mesta otkazalih TS i ekipa za održavanje, odustajanje od formiranja centralnih 
kontrolnih soba - tzv. distribuirani sistemi, veštačka inteligencija, ekspertni sistemi, sistemi za podršku odlučivanju, itd.);

- težište na obuci ljudstva. Danas se traži kadar sa znanjima iz više oblasti (vibracije, kompjuteri, elektronika...). Trend je na specijalizaciji ljudstva prema vrsti opreme, a manje prema strukama radne snage (klasična podela rada). Još izvesno vreme biće neophodna ljudska kontrola nad procesima, čak i u potpuno automatizovanim i robotizovanim postrojenjima. Obuka ljudstva trebalo bi da se organizuje bar 10 dana godišnje, uz korišćenje raspoloživih tehnologija, uključujući i predavanja na daljinu, preko računara;

- težnja ka 0-otkaza i 0-zastoja zbog održavanja, odnosno situacije kada će iznenadni otkazi biti samo izuzetni događaji a ne pravilo, odnosno činjenica, kao što je to slučaj danas. To se, prvenstveno, odnosi na važnu opremu, a ne na onu manje bitnu.

Ciljevi su da se:

- formalizuju pristupi menadžmentu rizikom (npr. tehnike kao: RCA - Root Cause Analyse), FMECA, Probabilistic Safety Assesment, Probabilistic Risk Assessment...);

- primene savremene strategije održavanja: održavanja prema pouzdanosti Reliability Centred Maintenance - RCM, totalno produktivno održavanje - Total Productive Maintenance (TPM) i drugih;

- integrišu uticaji ljudskog faktora (pouzdanost, greške, itd.);

- integriše participativni pristup u projektovanju opreme (npr. tehnike kao što su Design for Maintainability, Value Engineering, Hazop...).

Za domaću naučnu i stručnu javnost može biti samo privremeno utešno da is- kustva iz razvijenih zemalja [3] govore da se većina kompanija nalazi u drugoj generaciji sistema održavanja, a da su samo neke prešle u treću. Četvrta generacija je još uvek u domenu teoretskih razmatranja.

\section{Pokazatelji uspešnih sistema održavanja}

Pokazatelji da su neke faze dale rezultate, odnosno da je primena pojedinih postupaka - metoda za usavršavanje sistema održavanja bila efektivna, jesu sledeći $[4,5]$ :

- ne sme biti više od $25 \%$ neplaniranih poslova;

- planski poslovi bi trebalo da budu $95 \%$;

- plansko angažovanje 70\% raspoloživih resursa;

- dnevno raspoloživi kapaciteti moraju biti angažovani $100 \%$;

- obrt zaliha rezervnih delova trebalo bi da bude 3,0 do 3,5 (danas iznosi oko 0,7 );

- procenat traženih prema trenutno zadovoljenim zahtevima za rezervne delove trebalo bi da bude $97 \%$;

- da se $85 \%$ rezervnih delova i opreme za održavanje donosi na mesto rada;

- organizaciona celina koja se bavi upravljanjem i planiranjem ne treba da bude vezana za izvršni deo organizacije;

- planiranje se obavlja pre raspoređivanja poslova; poslovi se raspoređuju na one koji ih mogu izvršiti, a izvršenje poslova se ne prekida;

- postoji sistem za priorizaciju poslova; 
- planirani poslovi se izvršavaju na vreme;

- postoji preventivno održavanje koje se izvodi kada je jeftinije od korektivnog održavanja i većinom bez zaustavljanja rada TS;

- preventivne radnje održavanja izvršavaju se $100 \%$;

- baza tehničkih podataka je 95\% ažurna (postoji za sredstva) i tačna;

- korisnici učestvuju u sprovođenju radnji koje omogućavaju stvaranje osnovnih uslova za rad opreme (postoji „nega“ - opsluživanje TS);

- standardi sigurnosti su visoki (manje od 2 incidenta na 200000 radnih sati);

- postoji široki raspon kontrole, jer je kadar visokokvalifikovan, posebno na nivou poslovođa;

- svaki pojedinac ima poseban lični plan školovanja i usavršavanja;

- postoji posebna organizaciona celina koja se bavi sa RCA, FMECA i drugim naprednim tehnikama i direktno je odgovorna glavnom direktoru;

- u upravi sistema održavanja može se izdvojiti $20 \%$ radnog vremena za razvoj i rešavanje dugoročnih problema.

Prosečna ocena uspešnosti sistema održavanja preduzeća na Zapadu na skali od 1 do 10 je od 4 do 5, dok najbolji imaju ocenu 6, a retki 7 [5].

U svakom sistemu održavanja postoje mogućnosti za njegovo usavršavanje, kao i u izboru načina da se dođe do usavršavanja sistema i boljih rezultata funkcionisanja. Zbog toga je potrebno analizirati problem i ukazati na mogućnosti primene savremenih strategija održavanja, ali i drugih pristupa, bazirano na iskustvima $\mathrm{i}$ istraživanjima autora i podacima iz relevantne svetske literature.

\section{Uvođenje i korišćenje informacionog sistema}

Iako ne spada u strategije održavanja, Computerised Maintenance Management System (informacioni sistem za upravljanje održavanjem - CMMS) mora se uzeti u obzir, jer bez njega nema primene savremenih strategija održavanja, kao ni efektivnog i efikasnog menadžmenta održavanjem. Uvođenje ovog menadžerskog pomagala prvi je korak u usavršavanju svakog sistema održavanja.

Primena CMMS ima nekoliko prednosti, kao što su:

- služi kao podsetnik za organizovanje poslova u vremenu (Diary and Personal Organiser Tool), odnosno pruža podatke o poslovima, planovima, planiranim zastojima, troškovima, radnoj snazi, materijalu, TS, programima, rasporedima, statusu pojedinih poslova, potrebnoj dokumentaciji;

- raspoređuje radnu snagu prema zadacima, znanjima, ekipama ili na druge načine, i analizira njeno angažovanje;

- dnevno prati sve zahteve za održavanjem $i$ generiše radne naloge za preventivno održavanje;

- klasifikuje poslove prema prioritetima, lokacijama, TS,..;

- deli poslove na faze radi preciznijeg planiranja i programiranja;

- štedi vreme i novac (npr. ako u bazi podataka poseduje katalog delova i katalog ponuđača može se izabrati najbolja ponuda);

- prati troškove;

- prati ugovore za održavanje i njihovu realizaciju;

- vrši analizu otkaza TS, ali i preventivnog održavanja; 
- pomaže u određivanju trendova i drugim statističkim analizama;

- služi za obuku, učenje i davanje instrukcija (npr. ukoliko poseduje tehnološku dokumentaciju sa slikama, procedurama, specifikacijama materijala $\mathrm{i}$ opreme, itd.); ljudi;

- povećava bezbednost u radu TS i

- analizira prihode i rashode i omogućava racionalno praćenje trošenja budžeta;

- pomaže korisnicima tehničkih sredstava (može ih podsećati na njihove obaveze u vezi s opsluživanjem, pregledima ili planiranim zastojima).

Da bi se utvrdilo da li je postojeći sistem održavanja dobar, treba započeti sa njegovom analizom zasnovanoj na podacima iz CMMS [6]. Na ovaj način utvrđuje se i da li CMMS daje potrebne izlazne podatke. Ova analiza praktično se sastoji od dva koraka. Prvi korak je „Ocena“ koja se sastoji u dobijanju odgovora na sledeća pitanja:

1. Da li su preventivne procedure (akcije) svrsishodne (da li raste ili pada broj korektivnih akcija, koliko radnih časova se troši na korektivne, a koliko na preventivne akcije održavanja itd.)?

2. Da li se preventivno održavanje redovno vrši i kakvi su mu rezultati (na svakih 6 preventivnih akcija održavanja trebalo bi da se otkrije bar jedna korektivna)?

3. Gde su problemi vezani sa pouzdanošću (koja oprema, koji delovi i procesi najčešće otkazuju)?

4. Gde se troši najveći broj radnih časova službe održavanja (po različitim klasifikacijama vrsta poslova)?

5. Koliko je nedovršenih poslova (ukupna količina poslova ne bi smela da pređe veličinu koja se ne može završiti za 6 radnih nedelja) [7]?

6. Kolika je efikasnost radne snage u održavanju?

7. Koliko organizacija troši novca na održavanje i gde su problemi (kadar, delovi, oprema, podizvođači...)?

Drugi korak sastoji se u identifikaciji problema (prvenstveno vezano za CMMS), i obuhvata odgovore na pitanja:

1. Da li softver može da generiše potrebne liste i tabele i na koji način (npr. ako je izdvojeno više od 10 kritičnih vrsta TS to nije dobro)?

2. Da li je moguće dobiti pregled radne snage po potrebnim znanjima, veštinama, raspoloživim kapacitetima, itd.?

3. Kakav je pregled TS (identifikacioni brojevi, naziv, tip, model, starost, centri troškova, pripadnost organizacionim celinama, lokacija, itd.)?

4. Kakav je pregled zaliha (identifikacija, lokacija, isporučilac, minimalni i maksimalni nivo zaliha, itd.)?

5. Kakve su mogućnosti modula za izdavanje $i$ analizu radnih naloga?

6. Da li se u analizi preventivnih zadataka održavanja navode svi resursi potrebni za izvođenje akcija održavanja, da li postoji povratna veza, koliko je preventivna akcija bila efektivna, itd.)?

Dostupni podaci ukazuju na to da se investicije u uvođenje sistema CMMS vraćaju za 18 do 30 meseci [8].

\section{Primena savremenih strategija održavanja}

Pod tradicionalnim strategijama održavanja podrazumevaju se preventivno, korektivno i kombinovano održavanje. Savremene strategije su RCM, TPM, odr- 
Žavanje prema stanju, prediktivno održavanje i veći broj tzv. ,ubrzanih strategija“. Rezultati njihove primene su raznoliki.

Rezultati postignuti primenom strategije RCM, u različitim slučajevima, jesu sledeći [3]: smanjenje broja radnih časova za preventivno održavanje za $87 \%$; smanjenje ukupnog broja radnih časova za održavanje do $29 \%$; smanjenje troškova repromaterijala za održavanje do $64 \%$; povećanje raspoloživosti TS do $15 \%$; povećanje pouzdanosti TS do $100 \%$.

Poznato je da se investicije u RCM vraćaju za 3 do 6 meseci, eventualno godinu dana, i da se smanjuje broj zahteva za održavanje za 25 do $40 \%$. Međutim, za njegovu primenu potrebno je 2 do 6 godina, pošto su procedure analize, posebno FMECA, vrlo komplikovane, pa time i dugotrajne.

Kritičari primene ove strategije ističu da je ona namenjena za projektovanje TS, i da su joj ograničene mogućnosti za TS koji se već eksploatišu. Neki smatraju da je prekomplikovana i dugotrajna, posebno kada se do detalja razrađuje FMECA. RCM ne uzima $u$ obzir planiranje i planske zastoje TS, pa se smatra da je pogodna samo za komplikovane i složene TS.

Uvođenje strategije TPM zahteva puno vremena i uloženog rada. Prvi efekti su primetni već posle 6 meseci, dok puna implementacija traje više godina. Velike uspehe ovaj koncept je postigao pri primeni u kompanijama kao što su Ford, Kodak, Harley Davidson i Texas Instruments. Investicije se vraćaju za najmanje tri puta, a proizvodnja se u nekim slučajevima povećava i do $80 \%$, dok se zastoj zbog održavanja skraćuje i preko 50\% [9].

Ubrzane strategije održavanja nastale su kao odgovor na probleme prime- ne, prvenstveno RCM strategije, radi njihove brže primene i bržeg ostvarenja finansijskih rezultata.

Primena novih strategija održavanja zahteva promenu ,organizacione kultu$\mathrm{re}^{\text {" }} \mathrm{u}$ sredinama gde se primenjuje. To znači odustajanje od tradicionalnog razmišljanja orijentisanog na opravke i orijentaciju na pouzdanost, odnosno, pomak od reaktivnog ka proaktivnom načinu razmišljanja, što podrazumeva [10]: ciljeva;

- definisanje dugoročnih strategijskih

- usklađivanje sistema nagrađivanja sa strategijskim ciljevima;

- bolju integraciju proizvodnje (osnovne funkcije) i održavanja;

- stvaranje mogućnosti za timski rad i učenje;

- isključivo cilju posvećeno vođstvo - menadžment.

Razlike između tradicionalne organizacione kulture u održavanju i nove, koja mora nastati, prikazane su u tabeli [10].

Razlike izmedu tradicionalne organizacione kulture u održavanju i nove

\begin{tabular}{|c|c|}
\hline $\begin{array}{c}\text { STARO } \\
\text { Orijentacija na opravke }\end{array}$ & $\begin{array}{c}\text { NOVO } \\
\text { Orijentacija na pouzdanost }\end{array}$ \\
\hline Popravi & Unapredi \\
\hline „Gašenje požara“ & $\begin{array}{l}\text { Predvidi, Planiraj, } \\
\text { Programiraj akcije }\end{array}$ \\
\hline Zanatlija & Clan poslovnog tima \\
\hline Rešavaj otkaze & Eliminiši otkaze \\
\hline $\begin{array}{l}\text { Smanji troškove } \\
\text { održavanja }\end{array}$ & Povećaj vreme u radu \\
\hline $\begin{array}{l}\text { „Akcija-program } \\
\text { meseca“" }\end{array}$ & Kontinuirano unapređivanje \\
\hline $\begin{array}{l}\text { Verovanje da su otkazi } \\
\text { neizbežni }\end{array}$ & $\begin{array}{l}\text { Verovanje da su otkazi } \\
\text { samo izuzeci }\end{array}$ \\
\hline $\begin{array}{l}\text { Prioritet se daje } \\
\text { otkazima }\end{array}$ & $\begin{array}{l}\text { Prioritet se daje } \\
\text { eliminisanju uzroka otkaza }\end{array}$ \\
\hline Mnogo otkaza & Svega nekoliko otkaza \\
\hline $\begin{array}{l}\text { Nizak udeo planskih } \\
\text { poslova }\end{array}$ & $\begin{array}{l}\text { Visok udeo planskih } \\
\text { poslova }\end{array}$ \\
\hline Mnogo reklamacija & Malo reklamacija \\
\hline Niska pouzdanost & Visoka pouzdanost \\
\hline $\begin{array}{l}\text { Visoki troškovi } \\
\text { održavanja }\end{array}$ & Niski troškovi održavanja \\
\hline Kratkoročni planovi & Dugoročni planovi \\
\hline Neprofitni karakter & Privlači investicije \\
\hline
\end{tabular}


Da bi se ostvarile ove promene potrebno je 5 do 8 godina. Osnovno je napuštanje orijentacije sa neposrednih i kratkoročnih ciljeva i orijentacija ka dugoročnim ciljevima, a neophodna je i izvesna promena kadra. To podrazumeva i bolju motivaciju kadra i viši nivo inspiracije, jer traži zadovoljenje izmenjenih i viših psiholoških zahteva i potreba. Praktično, svaki zaposleni mora da nađe svoj interes u ovim promenama, pa se i sistem nagrađivanja podešava prema novim ciljevima organizacije.

Put od tradicionalnog pristupa održavanju ka savremenom pristupu ilustrovan je na slici 1 , na kojoj su prikazane faze u razvoju sistema održavanja. Jasno je da se pokazatelji uspešnosti poboljšavaju sa primenom novih pristupa. $U$ isto vreme menja se i sistem nagrađivanja, motivacioni mehanizmi i karakteristike ponašanja zaposlenih. Tako se, na primer, u reaktivnom okruženju smatra da se nikada ne zna šta je sledeći posao, novčane nagrade su vezane za prekovremeni rad na otklanjanju iznenadnih otkaza i hitnih poslova, ljudi postaju „heroji“ ako znaju nešto da oprave i to rade brzo, osnovnim kvalitetom službe održavanja smatra se brza reakcija na zahteve za opravkama. Jedino ograničenje je da se ne prekorači odobreni budžet, a sve aktivnosti usmeravaju se na jednostavne uštede. Veza između proiz-

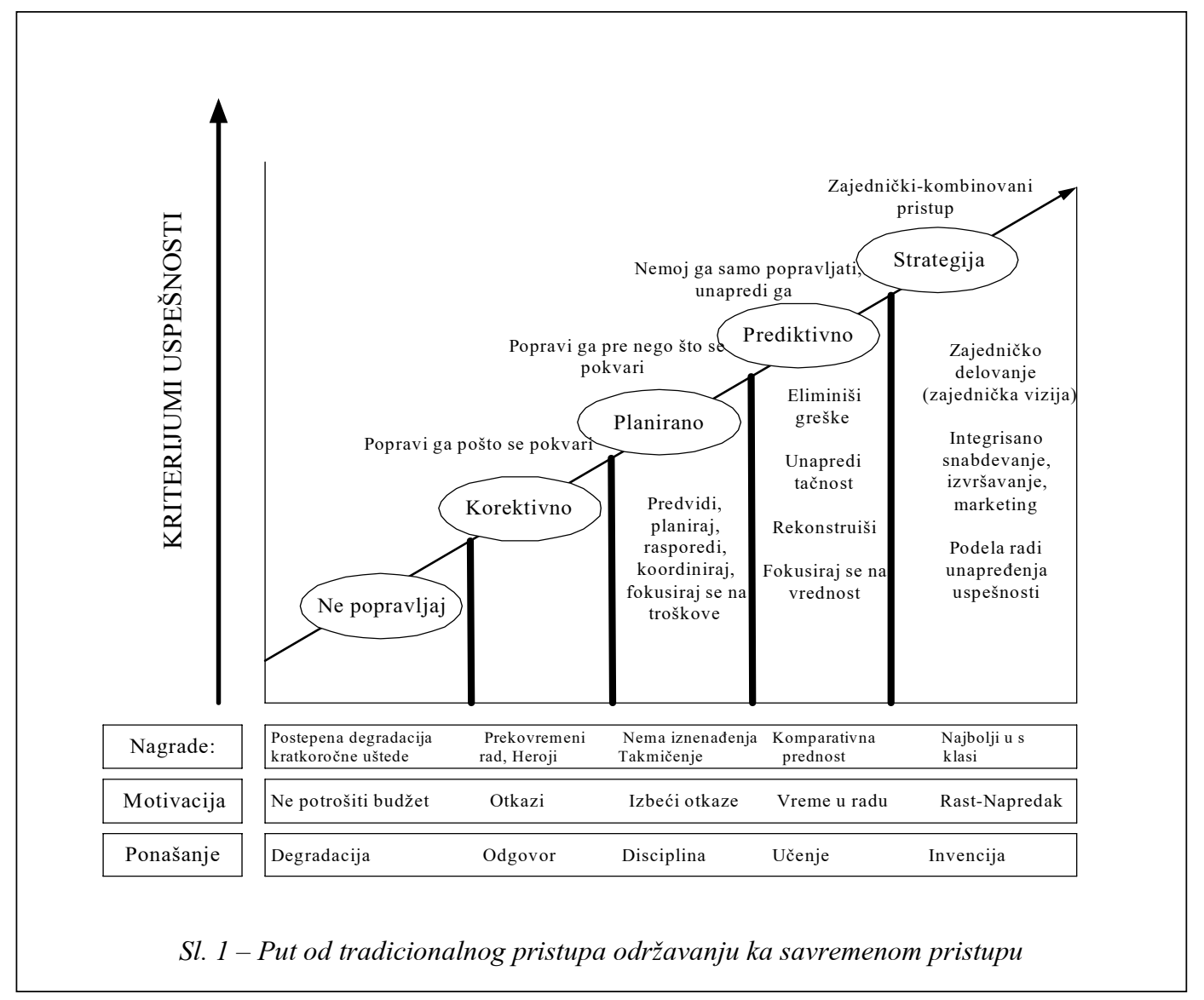


vodnje (osnovne funkcije) i održavanja svodi se na puko ispostavljanje zahteva za održavanjem.

Ukoliko se uvede strategija plansko-preventivnog održavanja menja se suština delovanja, jer se sada naglašava disciplinovano izvršavanje planiranih radova i procedura. Na taj način i stari sistem nagrađivanja više nije funkcionalan. Nagrađuju se oni koji posao obavljaju po tačno određenim procedurama i na vreme. Uvodi se pravilo ,što manje otkaza (manje rada u održavanju) veća plata“ ili fiksna plata, što eliminiše „,bivše heroje“ prekovremenog rada. Nagrađuje se postizanje planske raspoloživosti TS. Veza između proizvodnje i održavanja postaje dvosmerna, jer održavanje zahteva planske zastoje zbog izvođenja radnji održavanja.

U proaktivnom okruženju traži se učešće svih zaposlenih u otkrivanju mogućnosti za eliminaciju otkaza (strategije RCM, TPM,...). Međutim, pojavljuje se problem da se sa umanjenjem potreba za održavanjem umanjuje i potreban broj radne snage. To podrazumeva stvaranje sistema učešća ljudi u timovima za unapređenje rada, čime se kompenzuje njihovo neangažovanje na radovima održavanja. To zahteva i stvaranje sistema nenovčanih nagrada. Odnos proizvodnja - održavanje tada dobija nov kvalitet, jer se za određivanje „optimalnog“ održavanja zahteva učešće osoblja i iz proizvodnje i iz održavanja, kao i međusobna podela odgovornosti u ovom poslu (npr. za TPM). Stvaranje timova vitalni je element promena u ponašanju.

Poslednji stadijum ovog procesa još uvek ne postoji u praksi, ali je jasno da mu je suština u ostvarivanju sve veće integracije među delovima organizacije radi poboljšanja ukupnog poslovanja.
Na osnovu iznetih stavova može se zaključiti kojoj fazi razvoja pripada pojedini sistem održavanja.

Rešenje unapređenja uspešnosti sistema održavanja ne može se tražiti u primeni samo jedne strategije ili jedne metodologije. Svaka od njih ima određene prednosti, ali i nedostatke. Najbolji rezultati mogli bi se postići njihovom odgovarajućom kombinacijom [11], koja je, u skladu sa potrebama konkretne organizacije, cilj kojem treba da se teži. Pojedini pristupi efektivniji su od drugih u konkretnim uslovima, a opšte preporuke u tom smislu mogle bi se sintetizovati i grafički prikazati kao na slici 2. Metode i strategije primenjuju se u zavisnosti od faze razvoja pojedine organizacije održavanja.

Mnogi od ovih pristupa podrazumevaju veću integraciju i timski rad proizvodnje (osnovne funkcije), održavanja i projektovanja. Ograničenje je da se oni ne mogu uvesti niti sprovesti bez odgovarajuće edukacije, vođenja od najvišeg menadžmenta, istrajnosti, fleksibilnosti, promene organizacione kulture, javnosti rada i naglašavanja uspeha.

Pri svemu tome ne treba zaboraviti da se promene ne mogu uvoditi u sisteme koji „nisu spremni“ za njih. Na primer, kako uvesti nove preventivne radnje kada sistem za planiranje ne postoji, ili kako dobiti podatke o efektima pojedinih radnji kada ne funkcioniše povratna veza u informacionom sistemu, ili kako odrediti šta je hitno kada nema sistema za određivanje prioriteta? Redosled rešavanja pojedinih pitanja, odnosno problema, ilustrativno je prikazan $\mathrm{u}$ vidu piramide na slici 3 . U usavršavanju se kreće od baze ka vrhu piramide, a osnovicu daje sistem CMMS. 


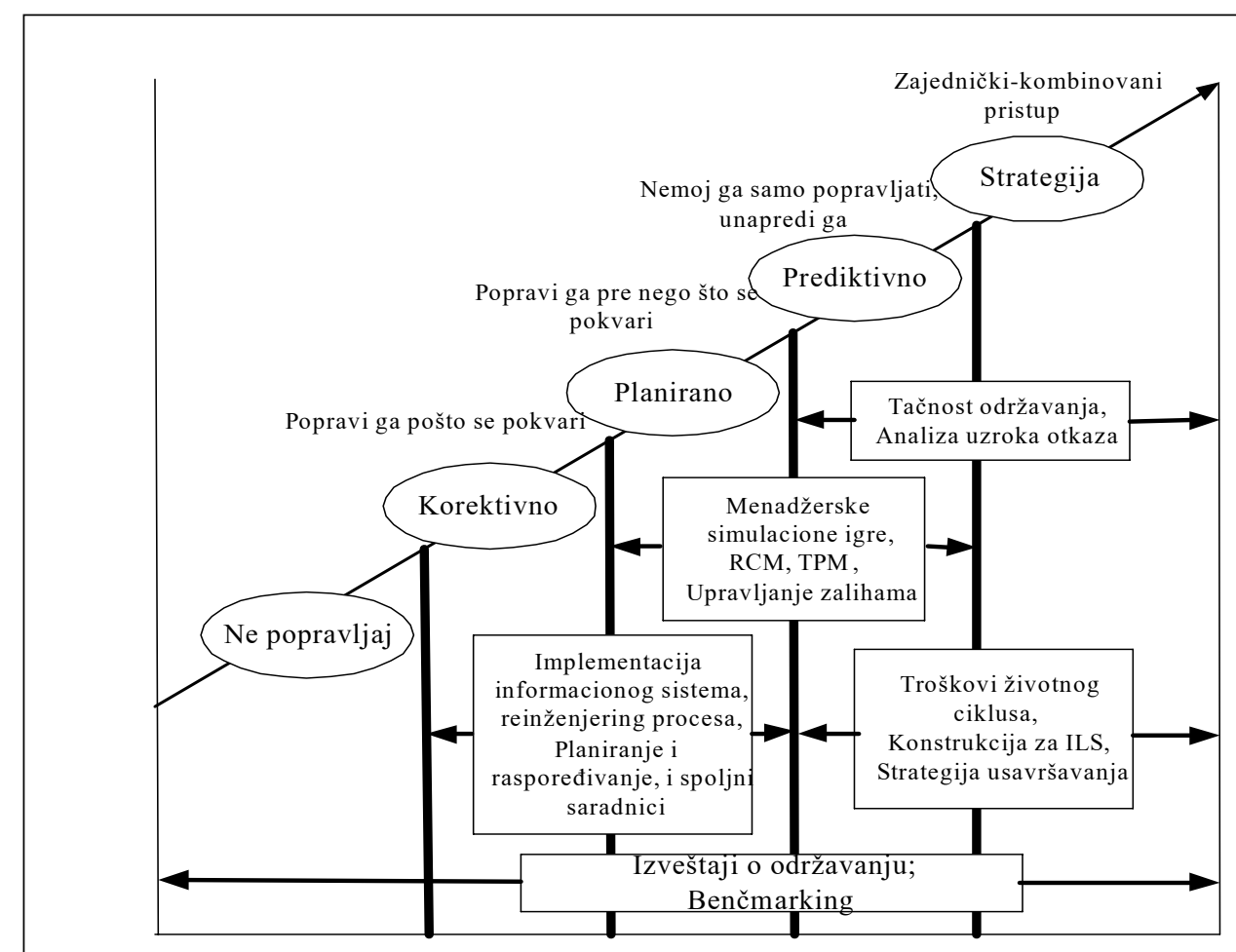

Sl. 2 - Metode i strategije koje se primenjuju u zavisnosti od faze razvoja pojedine organizacije održavanja

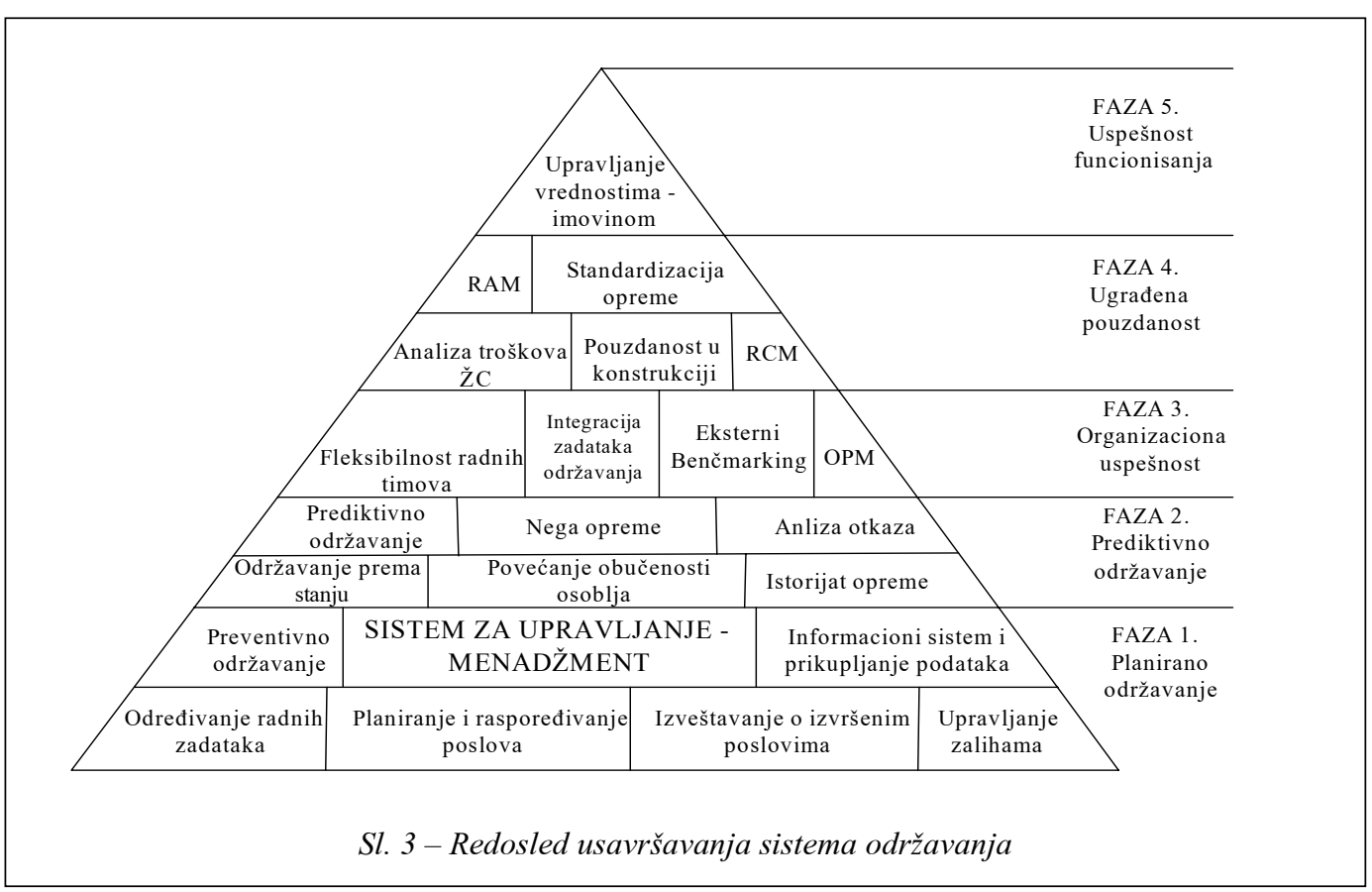


Pored prethodnih problema primena strategija održavanja, koji su više menadžerske prirode, odnosno vezani za organizaciju poslovanja, postoje i dva osnovna problema koji su više tehničko-tehnološke prirode. Prvi je u određivanju optimalnog intervala pregleda - inspekcije TS. U primeni savremenih strategija održavanja smatra se da tzv. ,prvu liniju odbrane" od otkaza čine postupci za dijagnostiku stanja TS [18] savremenom dijagnostičkom opremom. Međutim, što su pregledi - inspekcije češći, troškovi održavanja su veći. Ovaj problem ilustrovan je na slici 4. Svako TS, ili neki njegov deo, ima odgovarajući „životni vek“, odnosno period za koji će raditi u odgovarajućim granicama traženih performansi funkcionisanja. Neki delovi, odnosno oni kod kojih je moguće dijagnostikovati otkaz, od trenutka $\mathrm{P}$ daju signal o tome da je moguće da će doći do otkaza. U trenutku F taj deo definitivno otkazuje posle izvesnog perioda funkcionisanja uz smanjenje performansi (podebljana kriva na slici). Sa slike je jasno da je, ukoliko se oprema - deo pregleda $\mathrm{u}$ intervalima manjim od P-F, moguće da se ovaj otkaz otkrije pre nastanka.

Postavlja se pitanje koliko interval pregleda - inspekcije mora biti manji od intervala P-F. Takođe, postavlja se pitanje da li, ako se češće vrše pregledi - inspekcije, to znači da je i verovatnoća otkaza manja? Cilj bi bio da se otkaz otkrije neposredno pre vremena nastanka (ciljno vreme detekcije otkaza - slika 4), jer se na taj način maksimalno iskorišćava tzv. rezerva pouzdanosti TS - dela.

$\mathrm{Za}$ optimizaciju veličine intervala pregleda - inspekcija, ili zamene delova, razvijen je veliki broj matematičkih modela, tzv. modela održavanja. Oni su matematički veoma komplikovani, pa je važno uočiti sledeće stavove, uglavnom zasnovane na podacima iz literature [18]:

- ukoliko su troškovi preventivne zamene veći od troškova zastoja TS nema svrhe da se preventivno održavaju;

- ukoliko je metod za dijagnostiku otkaza potpuno pouzdan obavljanje više od jednog pregleda - inspekcije predstavlja gubljenje vremena i novca. Periodika takvog pregleda tada može biti

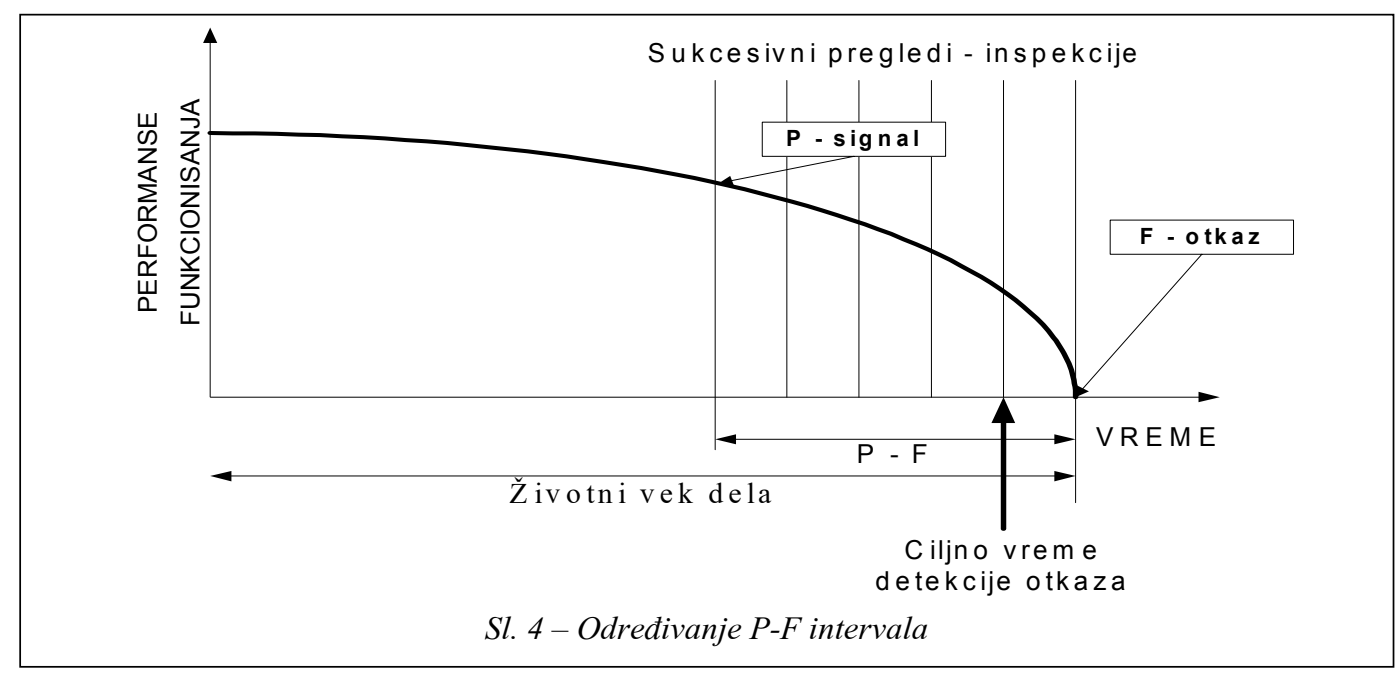




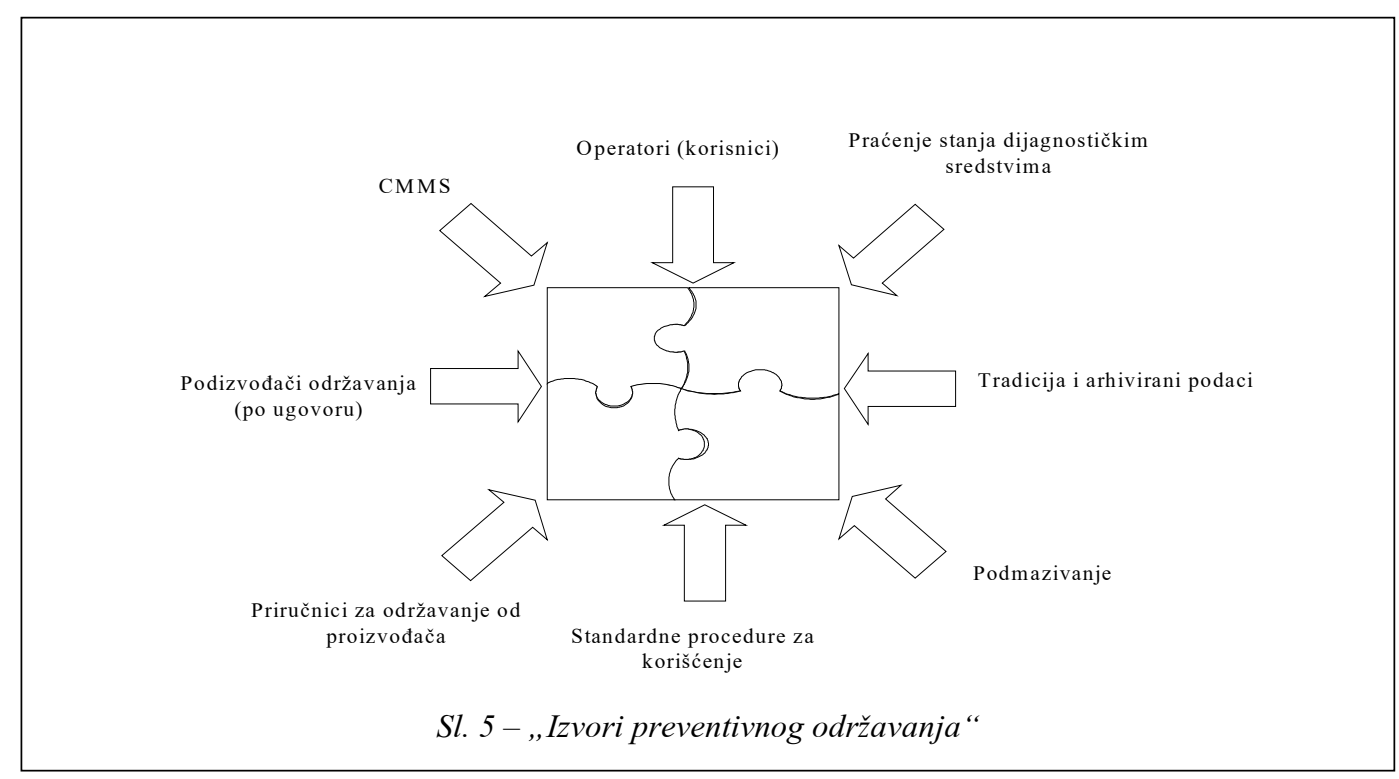

samo malo manja od intervala P-F. U protivnom pregledi - inspekcije moraju se vršiti češće, što zahteva optimizaciju broja pregleda u okviru intervala P-F;

- zagovornici primene RCM i TPM tvrde da korisnici opreme i ljudstvo iz procesa održavanja najbolje znaju, na osnovu iskustva, da odrede veličinu intervala P-F;

- suprotno od do skoro preovlađujućeg mišljenja u inženjerstvu održavanja, veličina optimalnog intervala pregleda inspekcije nije uslovljena verovatnoćom nastanka otkaza niti zakonitošću razvoja otkaza (degradacije dela).

Treba napomenuti da to važi za $91 \%$ delova koji bi mogli da se zamene pre nastanka otkaza (preventivno), a posebno oni koji daju „određeni signal“ da im je stanje narušeno.

Drugi problem tehničko-tehnološke prirode jeste kako optimizirati sadržaj preventivnih radnji održavanja. Tradicionalan pristup sastoji se u pridržavanju uputstava i preporuka proizvođača. Kao što je poznato, proizvođači, obično, preporučuju više radova sa većom učestalošću, što obično ne odgovara konkretnim uslovima korišćenja TS. Takođe, neke preporuke vremenom zastarevaju, kao što su na primer, one o zameni ulja, jer sa pojavom sintetičkih ulja kod motora sa unutrašnjim sagorevanjem interval zamene se višestruko povećao, ili one vezane za zastarelu opremu za dijagnostikovanje. Radi toga je potrebno najpre sagledati sve ,izvore podataka o preventivnom održavanju“ [19], kao što je to prikazano na slici 5 .

Potrebno je izvršiti određivanje ukupnog zadatka preventivnog održavanja (uključujući prioritete). Vrši se kompilacija akcija održavanja, odnosno prikupljanje i dokumentovanje postojećeg programa održavanja (formalnog - iz zvanične dokumentacije i neformalnog - iz iskustava korisnika i održavalaca TS). Zatim se analiziraju otkazi (oni koje postojeći sistem otklanja) sa stanovišta da se odbace one preventivne radnje koje otklanjaju otkaze koji se nikada neće dogoditi ili koji su neisplativi. Iz podataka o dosada- 
šnim otkazima određuje se na koje se otkaze isplati preventivno delovati, a nisu obuhvaćeni dosadašnjim preventivnim programom. Sledeći korak je racionalizacija preventivnih radnji i revizija svih relevantnih otkaza. U tom okviru vrši se eliminacija radnji koje se dupliraju u različitim preventivnim programima održavanja. Završni korak je analiza posledica dopuštenih otkaza, kako bi se odredili oni sa nedopustivim posledicama i odredio način preventivnog delovanja na njih. $\mathrm{Na}$ taj način stvara se ukupan racionalizovan optimiziran skup radnji preventivnog održavanja. U nekim slučajevima ovde je korisno primeniti FMECA analizu radi detaljnije analize kritičnih otkaza.

\section{Problemi i mogućnosti njihovog rešavanja u vojnim sistemima održavanja}

Za održavanje se izdvaja 5 do $10 \%$ od domaćeg vojnog budžeta. Ova sredstva su velika, ali su nedovoljna za trenutno potrebnu sanaciju tehnike. Međutim, koliko treba povećati budžet i da li to treba činiti ne bi bilo korisno odgovoriti pre određenog usavršavanja sistema održavanja usmerenog na neophodne racionalizacije. Na to ukazuju i određena svetska iskustva.

Avijacija mornarice SAD (NAVAIR) konstatovala je da joj troškovi održavanja rastu $5 \%$ godišnje. Po izveštajima njihove komande sadašnji rashodi vezani za eksploataciju i održavanje TS su reda veličine 50 do $60 \%$ od ukupnog budžeta. U uslovima restrikcije vojnih budžeta vrlo je teško održati borbenu spremnost $\mathrm{i}$ vršiti potrebne modernizacije. Zbog toga je u NAVAIR započeta realizacija projekta koji ima za cilj smanjenje troškova održavanja i eksploatacije (zasnovano na metodologiji RCM), pri čemu je definisan, prihvatljiv nivo raspoloživosti (gotovosti) tehnike [12].
Gotovo istovremeno ratna mornarica SAD, u okviru projekta Smart Ship (,inteligentni“ brod), na ratnom brodu USS YORKTOWN izvršila je implementaciju usavršenog sistema održavanja zasnovanog na RCM [13]. Smart Ship projekat zasniva se na: novim tehnologijama (ne samo za održavanje); novim politikama i procedurama (ne samo u održavanju) i novim metodama održavanja zasnovanim na RCM.

Konstatovano je da su postignuti sledeći rezultati: primenjena je fleksibilna matrična organizaciona struktura; izvršena je automatizacija navigacije, kontrole mašina, kontrole stanja mašina i opreme i informacionog sistema; smanjene su potrebe za preventivnim održavanjem za $15 \%$, a u isto vreme nije došlo do povećanja broja otkaza; ostvareno je smanjenje angažovanja radne snage za 9000 časova (30\%), što omogućava smanjenje posade za 44 mornara i 4 oficira, godišnje; novčane uštede mogle bi se estimirati na 2,865 miliona USD; povraćaj investicija u tehnologiju biće ostvaren za 17 godina, dok će se investicije u RCM vratiti za dve godine, itd. [14].

Britanska kraljevska mornarica u potpunosti je usvojila primenu RCM strategije, i u tu svrhu izdala odgovarajući standard.

Neki podaci o organizaciji italijanskih oružanih snaga govore o tome da kod njih postoji funkcija pomoćnika za naoružanje vezana za najviše vojno rukovodstvo, a koji ima delokrug rada koji upravo odgovara već pomenutoj funkciji „Asset management", odnosno njegov zadatak je upravljanje TS (naručivanje, nabavka, projektovanje, proizvodnja i održavanje). 
Podaci o stanju tehnike u našoj vojsci [15] govore o tome da još 1990 . godine, zbog nedostatka resursa, tehnički pregled nije izvršen na oko polovini TS, a izvršena je samo trećina od stvarnih potreba. Srednji i generalni remont realizovan je oko $50 \%$ od planiranog. Funkcionalna ispravnost tehnike tada je procenjivana vrlo visoko, ali je stanje bilo mnogo slabije. Realno je bilo očekivati da je bilo oko $2 / 3$ potpuno ispravnih tehničkih sredstava.

I pored evidentnog neizvršavanja radnji preventivnog održavanja, situacija po pitanju ispravnosti tehnike nije se znatno pogoršala ni posle izvođenja borbenih dejstava 1991/1992. godine. Iz toga se može zaključiti da je bilo predviđeno previše preventivnih radnji održavanja. U istom periodu smatralo se da je oko $60 \%$ neispravnosti na tehničkim sredstvima prouzrokovano slabim osnovnim održavanjem, što nameće zaključak da se uključivanjem korisnika u održavanje mogu postići izuzetno veliki efekti, što je suština strategije TPM.

U jednom istraživanju [16] procesa održavanja vozila TAM 110/150 devedesetih godina, što uključuje periode normalne eksploatacije i u toku izvođenja borbenih dejstava, uočeno je da je za pet godina od 4699 vrsta sastavnih delova otkazalo svega 300 . Od otkazalih delova samo 18 vrsta imalo je više od 20 otkaza, što predstavlja minimum zadat u standardu IEC 605 za izračunavanje intenziteta otkaza, odnosno pouzdanosti. Već sam podatak da je otkazalo svega 300 delova, a da je na zalihama, samo u jednoj jedinici, bilo oko 1000 različitih stavki, jasno ukazuje na mogućnosti ušteda kroz sma- njenje zaliha. Od 18 delova koji su najčešće otkazivali samo 6 ima jasno izraženu tendenciju rasta intenziteta otkaza, što govori da svega $2 \%$ delova spada u kategoriju onih kod kojih intenzitet nije konstantan. Sve to ukazuje na mogućnosti primene strategije RCM.

Zaključci koji su proizašli kao rezultat istraživanja $[15,17]$ vezanih za sistem održavanja u Vojsci ukazuju na činjenicu da se, na osnovu iznetih rezultata, može izvršiti rangiranje razmatranih faktora koji utiču na promenu pokazatelja uspešnosti funkcionisanja, i mogućnosti primene $u$ odnosu na potrebna ulaganja. Promenama u sistemu održavanja treba pristupiti prema redosledu značaja ovih faktora, odnosno takvim redosledom razvojnih koraka postigli bi se najveći efekti uz najmanja ulaganja. Ovaj redosled je, takođe, logičan, jer npr. bez uvođenja automatske obrade podataka i informacionog sistema nema efikasnog $\mathrm{i}$ efektivnog upravljanja zalihama r/d. Redosled razvojnih koraka (ili relevantnih faktora prema značaju) koje treba preduzeti je sledeći:

1. Može se tvrditi da je koncepcija strategija održavanja ključni faktor koji utiče na efektivnost i efikasnost sistema održavanja. Ukoliko se broj radova održavanja smanji za oko $40 \%$, raspoloživost opreme može se povećati za oko $30 \%$ (praktično koliko manje radnji održavanja toliko veća raspoloživost), a broj radnih mesta u održavanju smanjiti i do $10 \%$. Ovaj zaključak je i logički jasan, jer je jasno da će opredeljenje za strategiju održavanja uticati na karakter, obim i učestanost radova održavanja koje treba izvršiti u konkretnom sistemu. Šire gle- 
dano, ovde treba uključiti i primenu koncepta ILS (Integrated Logistics Support ili kod nas poznatiji kao ITOb).

2. Od pojedinačnih faktora najveću pažnju treba obratiti na skraćivanje administrativnih vremena kroz izmene u tipu i obliku upravljačke - organizacione strukture, i primenu savremene tehnologije za prenos i obradu informacija. Povećanje broja izvršenih radova za isto vreme $\mathrm{u}$ tom slučaju je oko $15 \%$, a rast pokazatelja raspoloživosti za do 5\%. To, kao i naredni stav, zahteva, pored redizajniranja organizacione strukture, postupaka i procedura za upravljanje, i uvođenje odgovarajućeg informacionog sistema (Computerised Maintenance Management System CMMS);

3. Naredni faktor po značaju je skraćenje logističkih vremena, posebno kroz određivanje optimalnog nivoa, načina upravljanja i rasporeda zaliha $\mathrm{r} / \mathrm{d}$ po nivoima, i ubrzavanje za njih vezanih materijalnih i informacionih tokova. Kao pogodna vrednost verovatnoće trenutnog zadovoljenja tražnje za rezervnim delovima navodi se vrednost od 0,70 do 0,85 .

4. Povećanje kvaliteta izvršenja radova održavanja više zahteva promene u ponašanju ljudi i organizaciji nego materijalna ulaganja. Na povećanje vrednosti pokazatelja raspoloživosti utiče oko 2 do $3 \%$.

5. Uvođenje i primena savremene dijagnostičke opreme svakako je jedan od najznačajnijih svetskih trendova (to je i sastavni deo opredeljenja za strategiju održavanja, bez čega se ne mogu odrediti potrebe za ovom vrstom opreme). Povećanje vrednosti pokazatelja raspoloživosti je oko $15 \%$ za $10 \%$ povećanja tačnosti dijagnostike.
6. Uvođenjem savremene remontne opreme (za rastavljanje, sastavljanje, itd.) raspoloživost bi se povećala za oko $1 \%$.

7. Ostali rezultati ukazuju na potrebu za što tačnijim dimenzionisanjem izvršnih i upravnih elemenata sistema održavanja, radi dodatnog smanjenja troškova.

Promene u sistemu navedenim redosledom bi, kako se dalje odmiče sa njihovom primenom, imale sve veći efekat na sistem, jer bi se uvećavao sinergetski efekat. Može se očekivati povećanje vrednosti pokazatelja uspešnosti do 30\%. Usavršavanja se mogu izvršiti i kombinacijom nekih navedenih koraka.

\section{Zaključak}

U usavršavanju sistema održavanja bitno je uočiti redosled kojim treba započeti taj proces. Pri svemu tome ne treba zaboraviti da se promene ne mogu uvoditi u sistemima koji „nisu spremni“ za njih. Pre uvođenja strategija održavanja treba usavršiti sistem planiranja radnji održavanja, informacioni sistem, menadžment, pravilno dimenzionisati sistem, obučiti radnu snagu, uvesti sistem za ocenjivanje uspešnosti rada i druga poboljšanja na polju menadžmenta održavanjem, pa tek onda uvoditi nove strategije održavanja, jer inače one neće naići na pripremljeno „tlo“ i mogu lako doživeti neuspeh.

Ključni, početni korak, za ozbiljnije racionalizacije ipak je stvaranje odgovarajuće strategije održavanja. U domenu strategija ne treba izgubiti iz vida da je svaki sistem održavanja specifičan i da zahteva posebna rešenja. Zbog toga se danas sve više teži kombinovanju postojećih strategija održavanja i drugih metoda, radi iskorišće- 
nja njihovih prednosti i smanjivanja nedostataka, a radi dobijanja adekvatnog i u konkretnoj praksi primenljivog rezultata. To podrazumeva da takav put treba tražiti i $\mathrm{u}$ našem vojnom sistemu održavanja.

$\mathrm{Ne}$ bi trebalo izgubiti iz vida da je naš vojni sistem održavanja, po slobodnoj proceni autora, negde između korektivnog i planiranog održavanja (slike 1 i 2). Da bi se pristupilo njegovom usavršavanju moraju se najpre rešiti problemi i nedostaci u oblastima koje su prikazane u dva najniža reda piramide na slici 3 . To podrazumeva uvođenje odgovarajućeg CMMS, sistema za upravljanje zalihama, povećanje kvaliteta radne snage, pribavljanje tehničke dokumentacije, opreme, itd. Tek nakon toga vredi krenuti ka stvaranju odgovarajuće strategije održavanja.

Literatura:

[1] Ray Beebe: It is the year 2020, and..., Reliability web.com, 2000

[2] John Woodhause: Asset management Decision-Making, The Woodhause Partnership Ltd., 2001.
[3] Sandy Dunn: Re-inventing the Maintenance Process, Queensleand Maintenance Conference, 1998.

[4] Dave Army: Operational Reliability Maturity Continum, Strategic Asset Management Inc., sami_01.htm

[5] Christer Idhammar: What constitutes world-class reliability and maintenance, Idcon Inc.

[6] Reliability Center, Inc.- Maintenance \& Engineering Notes.htm: The 9 Great Benefits of a CMMS, Reliability.web.com

[7] David Bertolini: Maxsimum CMMS, Reliability.web.com\

[8] John Woodhause: Asset management Decision-Making, The Woodhause Partnership Ltd., 2001.

[9] Ross Kennedy: Examining the Processes of RCM and TPM, Plant Maintenance Resource Center, 2002.

[10] Sandy Dunn: Moving from a Repair-focused to a Reliability-focused Culture, Reliability.web.com

[11] Evropski CRAFT projekat MELISSA (Maintenance Evaluation by Linked and Integrated Simulation in Sawmills), The Woodhause Partnership Ltd., 2001.

[12] Nancy Regan: U. S. Naval Aviation Implements RCM, Naval Air Warfare Center, Aircraft Div., 2000

[13] Smart Ship Project Assessment Report, 1998.

[14] Aleksić, M.: „Modernizacija krstarica tipa Ticonderoga“, Novi glasnik 3-4, VIZ Beograd, 2000.

[15] Projekat: Logistički pristup projektovanju VJ, 2000.

[16] Jovanović, D., Stanojević, P., Ćirović, M.: Neki problemi izučavanja pouzdanosti tehničkih sistema sa niskim i nestacionarnim intenzitetom eksploatacije, SYMOPIS, 1998.

[17] Stanojević, P., Bukvić, V. Mišković, V.: Pristup kvantifikaciji uticajnih faktora na sistem održavanja, NTP br.1., 2003.

[18] Steve Turner: Choosing maintenance analysis techniques, www.pmoptimisation.com

[19] Steve Turner: PM Optimisation (Maintenance Analysis of the Future), www.pmoptimisation.com 